\title{
EXTRAINTESTINAL MANIFESTATIONS OF CROHN'S DISEASE IN BANGLADESH
}

\author{
RAJIB BARUA ${ }^{1}$, DEWAN SAIFUDDIN AHMED ${ }^{2}$, A S M A RAIHAN ${ }^{3}$, MOHAMMAD ABUL KALAM AZAD $^{4}$, \\ SWADESH KUMAR CHAKROVORTTY $^{5}$, MD. ABUL KALAM AZAD ${ }^{6}$
}

\begin{abstract}
Crohn's disease has been considered to be uncommon in Asia Pacific region The study was undertaken to know the extraintestinal manifestations of Crohn's disease in Bangladesh and to compare the result with that of other Asian and Western countries. This was an observational study consisting of patients seen in the department of gastroenterology, Bangabandhu Sheikh Mujib Medical University for 20 years (between 1991 and 2010). Individual case records were carefully reviewed with regard to gender, sex and extraintestinal manifestations. A total of 41 patients with Crohn's disease were identified. $70.7 \%$ were male and $29.3 \%$ were female with male to female ratio was 2.4:1. Mean age was 34 11.8 years and peak age group was 21-30 years. The chief extraintestinal manifestations were arthritis, aphthous ulcer in the oral cavity, erythema nodosum and episcleritis. Arthritis was the most frequent among the extraintestinal manifestations. So, Crohn's disease should be considered as an important differential diagnosis when a patient presents with bowel symptoms associated with extraintestinal manifestation and thus early recognition and treatment could be possible.
\end{abstract}

Key words: Crohn's disaese, extraintestinal manifestation

\section{Introduction}

Crohn's disease is an inflammatory bowel disease that primarily affects small intestine and colon. Extraintestinal manifestations of inflammatory bowel disease are common, occuring in up to $25 \%$ of patients with inflammatory bowel disease. These manifestations can occur during periods of active inflammatory bowel disease and at any time unrelated to the activity of bowel disease. ${ }^{1}$ Crohn's disease has traditionally been considered a disease of developed countries and Asia-Pacific region had previously been thought as an area with a low incidence of Crohn's disease. More recent reports from India, Japan and China have shown it is an emerging disease in the part of the world where tuberculosis and infective colitis had previously been thought to predominate. ${ }^{2}$

The aim of the study was to find out the extraintestinal manifestations of Crohn's disease amongst Bangladeshi population and to identify any difference between the result in our population and that of other Asian as well as Western population.

\section{Materials and methods}

All patients attending the Gastroenterology department of Bangabandhu Sheikh Mujib Medical
University, Dhaka, Bangladesh with a diagnosis of Crohn's disease between 1991 and 2010 were enrolled in the study. Total forty one patients with Crohn's disease were included in the study. The medical records of these patients were thoroughly reviewed from the time of diagnosis up to the date of each patient's last follow up. Data were collected about gender, age at presentation and extraintestinal manifestations.

Data were entered systematically into computer with Microsoft Excel. The test statistics used to analyze the data were descriptive statistics.

\section{Results and observations}

A total of 41 patients diagnosed as Crohn's disease from 1991 to 2010 were reviewed. Twenty-nine patients $(70.7 \%)$ were males and twelve $(29.3 \%)$ were females. Male to female ratio was 2.4:1 (Figure 1). Age ranged from 18 to 70 years with a mean age of $34 \pm 11.8$ years (Mean $\pm \mathrm{SD}$ ). Of the total patients, 3 patients $(7.3 \%)$ were in $11-20$ years age group, 20 patients $(48.7 \%)$ were in $21-30$ years age group, 5 patients $(12.2 \%)$ were in $31-40$ years age group, 2 patients (4.9\%) were in 51-60 years age group and rest 1 patient $(2.4 \%)$ was in $61-70$ years age group (Figure 2). So the peak age group was 21-30 years.

1. Medical officer, Department of Gastroenterology, BSMMU

2. Associate Professor, Department of Gastroenterology, BSMMU

3. Professor, Department of Gastroenterology, BSMMU

4. Medical officer, Department of Medicine, BSMMU

5. Registrar, Department of Cardiology, NICVD

6. Associate Prof. Department of Medicine, BSMMU

Bangladesh J Medicine 2010; 21 : 58-59 


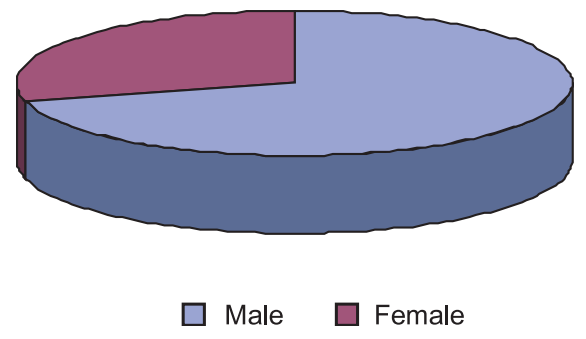

Fig.-2: Sex distribution of Crohn's disease

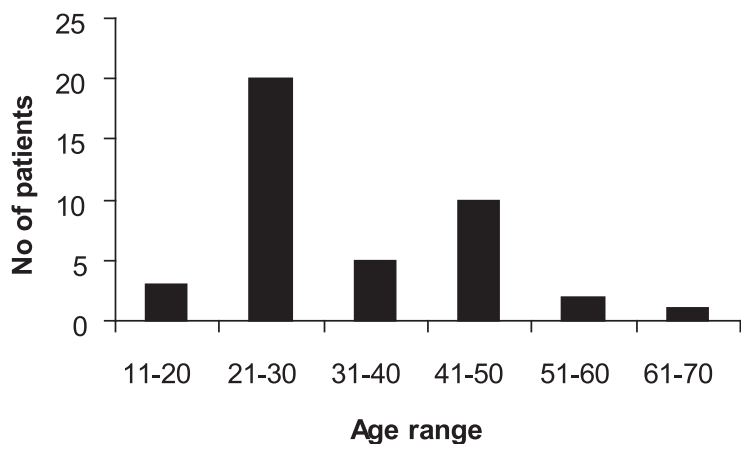

Fig.-3: Age distribution of Crohn's disease

The extraintestinal manifestations reported by the patients were arthritis, oral ulceration, ocular problem mostly episcleritis and erythema nodosum during the course of disease at the time of diagnosis or at different follow up. Most of the extraintestinal manifestations appeared during flare of intestinal manifestations and disappeared when intestinal manifestations achieved remission.

Out the total patients, 10 patients $(24.4 \%)$ patients had arthritis, 4 patients $(9.7 \%)$ patients had aphthous ulceration in the oral cavity, $2(4.9 \%)$ patients had erythema nodosum and $1(2.4 \%)$ had episcleritis (Table 1 )

Table-I

Extraintestinal manifestations of Crohn's disease ( $n=41)$

\begin{tabular}{lcc}
\hline Features & Number of patients & Percentage \\
\hline Arthritis & 10 & 24.4 \\
Aphthous ulcers & 4 & 9.7 \\
Erythema nodosum & 2 & 4.9 \\
Episcleritis & 1 & 2.4 \\
\hline
\end{tabular}

Arthritis found in Crohn's disesae were mostly peripheral asymmetrical oligoarticular involving the large joints of both upper and lower limbs. Pyoderma gangrenosum and primary sclerosing colangitis were not reported in our study.

\section{Discussion}

The present study was an observational study done in a referral, teaching hospital where we noticed the extraintestinal manifestations of Crohn's disease over the last two decades.

Extraintestinal manifestations in Crohn's disease are common in developed countries but uncommon in Asian countries like China (6.1\%) and Singapore. ${ }^{3}$ In Jewish patients with Crohn's disease, Sephardic patients had significantly more frequent extraintestinal manifestations than Ashkenazi patients $(35 \%$ vs. $17 \%) .{ }^{4}$ Extraintestinal manifestations were reported to be uncommon in patients with Crohn's disease from Pakistan. ${ }^{5}$ Arthritis was found in $24.4 \%$ of our patients, in $9.1 \%$ of Chinese patients, ${ }^{6}$ in 10 to $20 \%$ patients of developed countries. Erythema nodosum was found in $4.9 \%$ of our patients, in $3.1 \%$ of Chinese patients ${ }^{3}$ and in $6-15 \%$ of patients with Crohn's disease in developed countries. ${ }^{7}$ Oral ulceration occurred in $9.7 \%$ of our patients and in $4.9 \%$ of Chinese patients 6 whereas it was $70 \%$ in one report from a developed country. ${ }^{8}$ Finally, episcleritis was found in one of our patient $(2.4 \%)$, while in $2.3 \%$ Chinese patients $^{3}$ and Orchard et al reported 5\% in 483 Crohn's disease patients with more serious eye complications.

In conclusion arthritis in our patients was more frequent than other Asian countries but similar to Western countries. Extraintestinal manifestations other than arthritis are uncommon in our population

\section{References}

1. Judge TA, Lichtenstein GR. Inflammatory bowel disease. In: Friedman SL, McQuaid KR, Grendell $\mathrm{JH}$. Current diagnosis \& treatment in gastroenterology. 2nd edition. Mc Graw Hill 2003; 536-545.

2. Goh KL, Xiao SD. Inflammatory bowel disease: A survey of the epidemiology in Asia. Journal of Digestive Diseases 2009; 10: 1-6.

3. Wang YF, Zhang $\mathrm{H}$, Ouyang Q. Clinical manifestations of inflammatory bowel disease: East and West differences. J Dig Dis 2007; 8:121-27

4. Fidder HH, Avidan B, Lahav M, Bar-Meir S, Chowers Y. Clinical and demographic characterization of Jewish Crohn's disease patients in Israel. J Clin Gastroenterol 2003; 36: 8-12.

5. Abbas Z, Khan R, Abid S, Hamid S, Shah H, Jafri W. Is Crohn's disease in Pakistan less severe than in the West? Trop Doct 2004; 34: 39-41

6. APDW2004 Chinese IBD, Working Group. Retrospective analysis of 515 cases of Crohn's disease hospitalization in China: nationwide study from 1990 to 2003. J Gastroenterol Hepatol 2006; 21: $1009-1$

7. Orchard TR, Chua H, Jewell DP. Clinical feature of erythema nodosum (EN) and uveitis associated with inflammatory bowel disease. Gastroenterology 2000; 118: 755

8. Fujimura Y, Kamoi R, Iida M. Pathogenesis of aphthoid ulcers in Crohn's disease. Correlative findings by magnifying colonoscopy, electron microscopy, and immunohistochemistry. Gut 1996; 38: 724-32. 